\title{
Clinical factors and comorbidities affecting the cost of hospital-treated COPD
}

\author{
This article was published in the following Dove Press journal: \\ International Journal of COPD \\ 2 December 2016 \\ Number of times this article has been viewed
}

\author{
Sami Deniz' \\ Aysun Șengül2 \\ Yusuf Aydemir ${ }^{3}$ \\ Jülide Çeldir Emre ${ }^{4}$ \\ Mustafa Hikmet Özhan ${ }^{5}$ \\ 'Clinics of Chest Diseases, Dr Suat \\ Seren Chest Diseases and Thoracic \\ Surgery Education and Research \\ Hospital, Izmir, ${ }^{2}$ Clinics of Chest \\ Diseases, Kocaeli Derince Research \\ and Education Hospital, Kocaeli, \\ ${ }^{3}$ Department of Chest Diseases, \\ Sakarya University Faculty of \\ Medicine, Sakarya, ${ }^{4}$ Clinics of Chest \\ Diseases, Turgutlu State Hospital, \\ Manisa, ${ }^{5}$ Department of Chest \\ Diseases, Faculty of Medicine, Ege \\ University İzmir, Turkey
}

Purpose: We aimed to assess the effects of comorbidities on COPD costs and to investigate the relationship between comorbidities and clinical variables.

Patients and methods: All patients hospitalized with a diagnosis of COPD exacerbation between January 1, 2014, and December 31, 2014, at all state hospitals of Aydın province, a city located in the western part of Turkey, were included in this study. The costs examined in the study pertained to medications, laboratory tests, hospital stays, and other treatment-related factors, such as consumption of materials, doctor visits, and consultation fees.

Results: A total of 3,095 patients with 5,237 exacerbations (mean age, 71.9 \pm 10.5 years; 2,434 males and 661 females) were evaluated. For 880 of the patients $(28.9 \%)$, or 3,852 of the exacerbations (73.1\%), at least one comorbid disease was recorded. The mean cost of each exacerbation was $\$ 808.5 \pm 1,586$, including $\$ 325.1 \pm 879.9$ (40.7\%) for hospital stays, $\$ 223.1 \pm 1,300.9$ (27.6\%) for medications, $\$ 46.3 \pm 49.6(0.9 \%)$ for laboratory expenditures, and $\$ 214 \pm 1,068$ (26.5\%) for other treatment-related factors, such as consumption of materials, doctor visits, and consultation fees. The cost of each exacerbation was $\$ 1,014.9$ in patients with at least one comorbidity, whereas it was $\$ 233.6$ in patients without comorbidity $(P<0.001)$. Age $>65$ years, female gender, hospitalization in an intensive care unit, invasive or noninvasive mechanical ventilation, and a long duration of hospitalization were all found to be significant factors in increasing total costs during the exacerbations requiring hospitalization ( $P<0.05$ for all).

Conclusion: Comorbidities have an important role in the total costs of acute exacerbations of COPD. Strategies for the prevention, diagnosis, and effective management of comorbidities would decrease the overall financial burden associated with acute exacerbations of COPD.

Keywords: COPD, exacerbation, cost, comorbidity, morbidity, intensive care unit

\section{Introduction}

COPD, a common public health problem worldwide, is characterized by irreversible progressive airway obstruction and systemic inflammation as a result of exposure to smoking, noxious gases, and particles. ${ }^{1}$

According to the World Health Organization (WHO), COPD is the fourth most common cause of death and is estimated to be third by the year $2020 .^{2,3}$ In addition to its high mortality and morbidity rates, COPD is a very expensive disease and constitutes a significant liability to a nation's health care costs. For example, the annual cost of treatment for a patient with COPD is $\$ 9,981$ in the USA and $\$ 3,224$ in the UK. ${ }^{4}$ Because of continued exposure to COPD risk factors and an aging population, the global burden of COPD is expected to increase further in the coming years.

The main cost load of COPD consists of acute exacerbations, a finding that has been highlighted in studies conducted in Turkey. ${ }^{5-7}$ On average, patients with COPD experience one to three exacerbations per year. These exacerbations comprise the
Correspondence: Yusuf Aydemir Department of Chest Diseases, Sakarya University Faculty of Medicine, Hastane Caddesi, 54100 Sakarya, Turkey Tel +00905056369494 Email dryaydemir@yahoo.com 
main reason for emergency department treatment and hospitalization. Acute exacerbations adversely affect the prognosis of the disease and accelerate the process of severe respiratory failure. Also, exacerbations become more frequent and more severe as the disease progresses. ${ }^{8,9}$ In turn, severe COPD exacerbations requiring mechanical ventilation and intensive care trigger higher costs.

Another important component of COPD-related costs is the disease's comorbidities. Multisystem involvement with significant extrapulmonary manifestations is associated with COPD, and patients frequently suffer from comorbidities such as cardiovascular disease, osteoporosis, depression, malnutrition, metabolic syndrome, diabetes, and lung cancer. ${ }^{1}$ These comorbidities have a major impact on the patient's quality of life and survival. Previous reports have shown that $>60 \%$ of COPD patient deaths are caused by comorbidities rather than by COPD itself. ${ }^{10,11}$

Although the high costs associated with COPD and the disease's comorbidity rates are well known, ${ }^{12,13}$ studies on the effects of comorbidities on the disease's costs are both limited and controversial. ${ }^{14-17}$ However, the management of comorbidities and their prevention might provide some benefit in reducing the global cost load. Accordingly, in this study, we aimed to assess the effects of comorbidities on COPD costs and to investigate the relationship between comorbidities and clinical variables such as age, gender, and the requirement of intensive care or mechanical ventilation.

\section{Patients and methods Study design and population}

This retrospective descriptive case-series study included all patients older than 40 years who were hospitalized with a diagnosis of COPD exacerbation between January 1, 2014, and December 31, 2014, at all state hospitals of Aydin province, a city located on the Aegean Seacoast in the western part of Turkey and having a population of one million. In this study, COPD exacerbation was defined as an acute change in baseline dyspnea as well as cough and/or sputum production. ${ }^{1}$ Patients who were admitted to a hospital more than once were excluded. The study was approved by the Institutional Ethics Committee of Adnan Menderes University Faculty of Medicine (no 2015/617). The informed consent requirement was waived by the Institutional Ethics Committee due to the study's retrospective design.

\section{Study procedures and data collection}

The data on demographics, diagnoses, comorbid diseases, treatment procedures, total costs and a breakdown of cost per exacerbation, hospitalization duration, length of intensive care unit stay, and spirometric measures were obtained from the hospitals' databases.

The costs examined in the study pertained to medications, laboratory tests, hospital stays, and other treatment-related factors such as consumption of materials, doctor visits, and consultation fees. Costs recorded as Turkish lira (TL) in the hospital data were converted into US dollars based on 2014 average currency ( $1 \$$ was equal to $2.24 \mathrm{TL}$ in 2014 and to $3.06 \mathrm{TL}$ in 2016).

\section{Statistical analysis}

The study data were summarized by the descriptive statistics (mean, standard deviation, minimum, median, maximum, frequency, and percentage). The difference between two independent groups showing a nonnormal distribution was investigated using Mann-Whitney $U$ test. The relation between categorical variables was tested either by the chisquare test or by the Fisher's exact test. A linear regression analysis was performed to estimate the relation between the cost and duration of a hospitalization. The level of statistical significance was determined as 0.05 . Analyses were performed using the MedCalc statistical software program (Version 12.7.7; MedCalc Software bvba, Ostend, Belgium; http://www.medcalc.org; 2013).

\section{Results Study patients}

A total of 3,095 patients with 5,237 exacerbations (mean

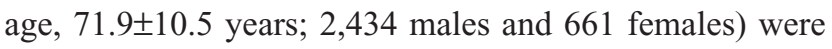
evaluated. The patients' mean forced expiratory volume per 1 second $\left(\mathrm{FEV}_{1}\right)$ was $32 \% \pm 4.8 \%$.

\section{Cost of COPD exacerbations}

The mean cost of each exacerbation was $\$ 808.5 \pm 1,586$ including $\$ 325.1 \pm 879.9$ (40.7\%) for hospital stays, $\$ 223.1 \pm 1,300.9(27.6 \%)$ for medications, $\$ 46.3 \pm 49.6(0.9 \%)$ for laboratory expenditures, and $\$ 214 \pm 1,068$ (26.5\%) for other treatment-related factors, such as consumption of materials, doctor visits, and consultation fees. The portion of antibiotic expenditures included in the medication costs was $\$ 44.4 \pm 94.4$ on average (Table 1).

Eight hundred forty-one of the exacerbations required hospitalization in intensive care units. For 303 of these attacks, invasive mechanical ventilation was applied, whereas noninvasive mechanical ventilation was applied in 406 cases, and 130 cases were followed up solely by monitoring. The cost related to the exacerbations requiring stays in intensive care units was 
Table I The breakdown of the costs for COPD exacerbations

\begin{tabular}{lll}
\hline Variable & $\begin{array}{l}\text { Cost in \$ (mean } \pm \\
\text { standard deviation) }\end{array}$ & $\begin{array}{l}\text { Breakdown } \\
\text { of cost (\%) }\end{array}$ \\
\hline Cost of hospital stay & $325.1 \pm 879.9$ & 40.7 \\
Cost of medication & $223.1 \pm 1,300.9$ & 27.6 \\
Cost of laboratory & $46.3 \pm 49.6$ & 0.9 \\
$\begin{array}{l}\text { Other costs (consumption } \\
\text { materials, doctor visits, }\end{array}$ & $214 \pm 1,068$ & 26.5 \\
and consultation fee) & & \\
Total cost & $808.5 \pm 1,586$ & 100 \\
\hline
\end{tabular}

$\$ 1,978 \pm 2,459$. The mean duration of hospitalization for all exacerbations was $8.1 \pm 6.3$ days, whereas it was $10.4 \pm 8.9$ days for those of patients hospitalized in intensive care units.

Age $>65$ years, female gender, hospitalization in an intensive care unit, invasive or noninvasive mechanical ventilation, and a long duration of hospitalization were all found to be significant factors in increasing total costs during the exacerbations requiring hospitalization $(P<0.05$ for all) (Table 2). The duration of hospitalization was positively correlated with all costs, including laboratory $(r=0.220$, $P<0.001)$, medication $(r=0.681, P<0.001)$, hospital stay $(r=0.712, P<0.001)$, and total $(r=0.660, P<0.001)$ costs.

\section{Cost of comorbidities}

For 880 of the patients (28.9\%), or 3,852 of the exacerbations $(73.1 \%)$, at least one comorbid disease was recorded. The comorbidities constituted hypertension in 780 patients
(25.2\%), congestive heart failure in 645 patients $(20.8 \%)$, coronary artery disease in 637 patients $(20.6 \%)$, diabetes mellitus in 628 patients $(20.3 \%)$, anemia in 501 patients (16.2\%), gastroesophageal reflux in 348 patients (11.2\%), anxiety/depression in 467 patients (15.1\%), arrhythmia in 213 patients $(6.9 \%)$, lung cancer in 58 patients $(1.9 \%)$, pulmonary thromboembolism in 44 patients $(1.4 \%)$, chronic renal failure in 25 patients $(0.8 \%)$, cachexia in 91 patients $(2.9 \%)$, obesity in 88 patients $(2.8 \%)$, and osteoporosis in 211 patients $(6.8 \%)$ (Figure 1).

Total cost was significantly higher in patients with exacerbations accompanied by any comorbidity than in those having no comorbidity. Considering comorbid diseases, total cost was found to be statistically and significantly much higher in cases with pneumonia, diabetes mellitus, cardiac failure, hypertension, coronary artery disease, anemia, lung cancer, arrhythmia, anxiety/depression, and osteoporosis (Table 3).

\section{Discussion}

COPD is a disease that affects patients' quality of life due to its progressive and continuously symptomatic nature. Almost all patients have reduced physical activity, and they experience two or more symptoms every day. For this reason, patients with COPD must continuously use a high volume of medications, which produces a significant cost load. Although the possibility of reducing the cost of chronic medication is low, exacerbations might be reduced or prevented. Exacerbations

Table 2 The relationship between demographic/clinical variables and the cost

\begin{tabular}{|c|c|c|c|c|c|}
\hline Variable & $\mathbf{n}$ & Cost of laboratory (\$) & Cost of medication (\$) & Cost of hospital stay $(\$)$ & Total cost (\$) \\
\hline \multicolumn{6}{|l|}{ Age (years) } \\
\hline$<65$ & 1,193 & $44.4 \pm 52.4$ & $200.4 \pm 637.5$ & $293.5 \pm 754.9$ & $738.9 \pm 1,368$ \\
\hline$\geq 65$ & 4,044 & $46.8 \pm 48.8$ & $229.9 \pm 1,439.7$ & $334.5 \pm 913.8$ & $829.1 \pm I, 644.7$ \\
\hline$P$-value & & 0.004 & 0.076 & $<0.001$ & 0.003 \\
\hline \multicolumn{6}{|l|}{ Gender } \\
\hline Female & 841 & $58 \pm 60.8$ & $175.7 \pm 460.7$ & $399.1 \pm 1,019.1$ & $922.5 \pm 1,597.5$ \\
\hline Male & 4,396 & $44.1 \pm 46.9$ & $232.2 \pm 1,405.4$ & $311 \pm 850.5$ & $786.8 \pm 1,583$ \\
\hline$P$-value & & $<0.001$ & $<0.001$ & $<0.001$ & $<0.001$ \\
\hline \multicolumn{6}{|c|}{ Intensive care stay } \\
\hline Absent & 4,396 & $39.6 \pm 40.7$ & $205.2 \pm I, 149.6$ & $200.3 \pm 494.6$ & $584.9 \pm 1,236.8$ \\
\hline Present & 841 & $84.1 \pm 7 \mid$ & $316.6 \pm 1,910.5$ & $976.2 \pm 1,749.1$ & $1,976.2 \pm 2,465.1$ \\
\hline$P$-value & & $<0.001$ & $<0.00 \mathrm{I}$ & $<0.001$ & $<0.001$ \\
\hline \multicolumn{6}{|l|}{ Intubation } \\
\hline Absent & 4,932 & $43.1 \pm 45.5$ & $205 \pm 1,095.3$ & $232.9 \pm 477.5$ & $656.1 \pm 1,232.6$ \\
\hline Present & 305 & $97.5 \pm 78$ & $516.6 \pm 3,099.8$ & $I, 816 . I \pm 2,697$ & $3,273.3 \pm 3,495.8$ \\
\hline$P$-value & & $<0.001$ & $<0.001$ & $<0.001$ & $<0.001$ \\
\hline \multicolumn{6}{|c|}{$\begin{array}{l}\text { Noninvasive mechanical } \\
\text { ventilation }\end{array}$} \\
\hline Absent & 4,831 & $43.7 \pm 47.6$ & $215.8 \pm 1,339.7$ & $290.3 \pm 888.6$ & $730.7 \pm 1,562$ \\
\hline Present & 406 & $76.9 \pm 61.6$ & $310.3 \pm 689$ & $739.5 \pm 642.6$ & $\mathrm{I}, 735.7 \pm \mathrm{I}, 58 \mathrm{I}$ \\
\hline$P$-value & & $<0.001$ & $<0.001$ & $<0.001$ & $<0.001$ \\
\hline
\end{tabular}




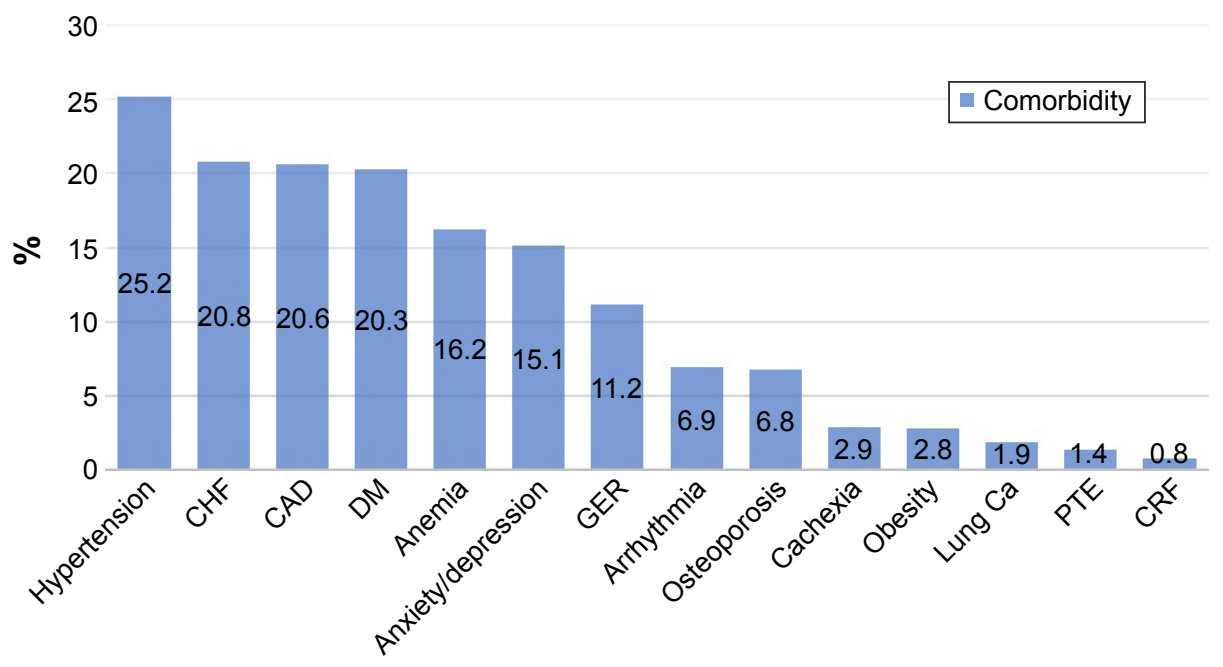

Figure I The prevalence of comorbidities.

Abbreviations: $\mathrm{Ca}$, cancer; CAD, coronary artery disease; CHF, congestive heart failure; CRF, chronic renal failure; DM, diabetes mellitus; GER, gastroesophageal reflux; PTE, pulmonary thromboembolism.

Table 3 Diseases concomitant to COPD exacerbations and their effects on the cost

\begin{tabular}{|c|c|c|c|c|c|}
\hline Kind of comorbidity & $\mathbf{n}$ & Cost of laboratory (\$) & Cost of medication (\$) & Cost of hospital stay (\$) & Total cost (\$) \\
\hline \multicolumn{6}{|l|}{ Pneumonia } \\
\hline Absent & 4,297 & $44.6 \pm 46.8$ & $206.5 \pm 1,151.3$ & $291.1 \pm 667.1$ & $726 \pm 1,281.3$ \\
\hline Present & 940 & $53.7 \pm 60.4$ & $229.2 \pm I, 835.4$ & $480.5 \pm I, 50 \mathrm{I} .6$ & $1,185.9 \pm 2,519$ \\
\hline$P$-value & & $<0.001$ & $<0.001$ & $<0.001$ & $<0.001$ \\
\hline \multicolumn{6}{|l|}{ Diabetes } \\
\hline Absent & 4,182 & $42.5 \pm 46$ & $|82.6 \pm 1| 34.8$, & $245.3 \pm 524$ & $630.2 \pm 1,114.5$ \\
\hline Present & $\mathrm{I}, 055$ & $61.1 \pm 59.1$ & $383.8 \pm I, 808.8$ & $641.5 \pm 1,623$ & $\mathrm{I}, 5 \mathrm{I} 5.5 \pm 2,635.3$ \\
\hline$P$-value & & $<0.00 \mathrm{I}$ & $<0.001$ & $<0.001$ & $<0.001$ \\
\hline \multicolumn{6}{|l|}{ Heart failure } \\
\hline Absent & 4,252 & $40.7 \pm 42.9$ & $\mid 88.2 \pm 1,366.4$ & $222 \pm 63.1$ & $583.3 \pm 9,425.6$ \\
\hline Present & 985 & $70.6 \pm 66.7$ & $374.3 \pm 955.9$ & $770.1 \pm 1,660.4$ & I,780.8 $\pm 2,894.2$ \\
\hline$P$-value & & $<0.001$ & $<0.001$ & $<0.001$ & $<0.001$ \\
\hline \multicolumn{6}{|l|}{ Hypertension } \\
\hline Absent & 4,040 & $38.7 \pm 38.75$ & $|64.7 \pm 1,35| .7$ & $194.3 \pm 423.9$ & $502.2 \pm 750$ \\
\hline Present & I, 197 & $72 \pm 69.8$ & $420.3 \pm 1,091.7$ & $766.5 \pm 1,591$ & $\mathrm{I}, 84 \mathrm{I} \pm 2,780.5$ \\
\hline$P$-value & & $<0.001$ & $<0.001$ & $<0.001$ & $<0.00 \mathrm{I}$ \\
\hline \multicolumn{6}{|l|}{ Coronary artery disease } \\
\hline Absent & 4,225 & $40.6 \pm 40.8$ & $|65.8 \pm 1,08| .8$ & $211.3 \pm 544.9$ & $553.1 \pm 984.3$ \\
\hline Present & 1,012 & $70.1 \pm 71.1$ & $462.7 \pm I, 95 I . I$ & $800.3 \pm 1,578.6$ & $|, 875 . I \pm 2,75| .3$ \\
\hline$P$-value & & $<0.00 \mathrm{I}$ & $<0.001$ & $<0.001$ & $<0.001$ \\
\hline \multicolumn{6}{|l|}{ Anemia } \\
\hline Absent & 4,510 & $40.8 \pm 40.9$ & 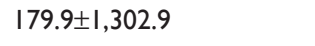 & $213.7 \pm 699.3$ & $595.4 \pm 1,133$ \\
\hline Present & 727 & $80.4 \pm 77.5$ & $489.2 \pm I, 258.8$ & $904.9 \pm 1,469.6$ & $2,|3| .2 \pm 2,852.4$ \\
\hline$P$-value & & $<0.001$ & $<0.00 \mathrm{I}$ & $<0.00 \mathrm{I}$ & $<0.001$ \\
\hline \multicolumn{6}{|l|}{ Reflux } \\
\hline Absent & 4,608 & $46.6 \pm 50.7$ & $225 \pm I, 375.5$ & $315.8 \pm 898.6$ & $795.1 \pm 1,622.9$ \\
\hline Present & 629 & $44.2 \pm 41.2$ & $209.7 \pm 483.4$ & $393.2 \pm 728.7$ & $906.4 \pm 1,281.8$ \\
\hline$P$-value & & 0.982 & $<0.001$ & $<0.001$ & $<0.001$ \\
\hline \multicolumn{6}{|l|}{ Lung cancer } \\
\hline Absent & 5,143 & $46.1 \pm 49.7$ & $213.1 \pm 1,078.6$ & $325 \pm 884.2$ & $806.5 \pm 1,589.7$ \\
\hline Present & 94 & $54.6 \pm 47$ & $771.9 \pm 5,539.3$ & $331.3 \pm 629.2$ & $919.6 \pm 1,387.4$ \\
\hline$P$-value & & $<0.001$ & $<0.001$ & $<0.001$ & $<0.001$ \\
\hline
\end{tabular}


Table 3 (Continued)

\begin{tabular}{|c|c|c|c|c|c|}
\hline Kind of comorbidity & $\mathbf{n}$ & Cost of laboratory (\$) & Cost of medication (\$) & Cost of hospital stay (\$) & Total cost (\$) \\
\hline \multicolumn{6}{|c|}{ Pulmonary thromboemboli } \\
\hline Absent & 5,158 & $46.3 \pm 49.7$ & $219.6 \pm 1,289.6$ & $323 \pm 862.1$ & $803.6 \pm 1,556.2$ \\
\hline Present & 79 & $44.1 \pm 44.3$ & $450.1 \pm 1,910.6$ & $462.1 \pm I, 687.8$ & $\mathrm{I}, \mathrm{II} 0.8 \pm 3,639$ \\
\hline$P$-value & & 0.011 & 0.006 & 0.126 & 0.028 \\
\hline \multicolumn{6}{|l|}{ Arrhythmia } \\
\hline Absent & 4,903 & $45.7 \pm 48.6$ & $215.7 \pm 1,327.1$ & $311.1 \pm 883.5$ & $774.8 \pm I, 574.8$ \\
\hline Present & 333 & $55.4 \pm 62.7$ & $332.8 \pm 821.3$ & $531.9 \pm 802.9$ & $\mathrm{I}, 306.9 \pm \mathrm{I}, 67 \mathrm{I} .7$ \\
\hline$P$-value & & 0.001 & $<0.001$ & $<0.001$ & $<0.001$ \\
\hline \multicolumn{6}{|l|}{ Malnutrition } \\
\hline Absent & 5,072 & $46.3 \pm 49.7$ & $224 . I \pm I, 32 I$ & $324.2 \pm 85.4$ & $807 \pm 1,602.7$ \\
\hline Present & 165 & $47.8 \pm 46.3$ & $194 \pm 305$ & $354 \pm 546.3$ & $858 \pm 952.1$ \\
\hline$P$-value & & 0.495 & 0.155 & 0.001 & 0.003 \\
\hline \multicolumn{6}{|l|}{ Obesity } \\
\hline Absent & 5,089 & $46 \pm 49.33$ & $220.5 \pm 1,313$ & $324.4 \pm 888.3$ & $804.6 \pm 1,594.3$ \\
\hline Present & 148 & $54.4 \pm 58.9$ & $314.5 \pm 788.9$ & $349.1 \pm 84.6$ & $954.4 \pm 1,272.5$ \\
\hline$P$-value & & 0.150 & 0.005 & 0.042 & 0.014 \\
\hline \multicolumn{6}{|l|}{ Anxiety/depression } \\
\hline Absent & 4,173 & $42.3 \pm 46.3$ & $20 I \pm I, 162.8$ & $289.8 \pm 925$ & $729.6 \pm 1,655.7$ \\
\hline Present & 1,063 & $61.8 \pm 58.5$ & $310 \pm 1,740$ & $463.9 \pm 658.9$ & $\mathrm{I}, \mathrm{I} \mid \mathrm{I} .7 \pm \mathrm{I}, 230.8$ \\
\hline$P$-value & & $<0.001$ & $<0.001$ & $<0.001$ & $<0.001$ \\
\hline \multicolumn{6}{|l|}{ Osteoporosis } \\
\hline Absent & 4,952 & $45.5 \pm 48.7$ & $222.8 \pm 1,334.7$ & $310.5 \pm 818.9$ & $784.5 \pm I, 548 . I$ \\
\hline Present & 285 & $59.5 \pm 61.4$ & $227.9 \pm 396.1$ & $578.4 \pm I, 589.5$ & $1,226.5 \pm 2,102.6$ \\
\hline$P$-value & & $<0.001$ & 0.001 & $<0.001$ & $<0.001$ \\
\hline \multicolumn{6}{|l|}{ Total comorbidities } \\
\hline Absent & 1,383 & $27.5 \pm 22.94$ & $120 \pm 1,744.6$ & $79 \pm 101.2$ & $233.6 \pm 176.5$ \\
\hline Present & 3,852 & $53 \pm 54.6$ & $260.1 \pm 1,097.1$ & $4 \mid 3.4 \pm I, 009.4$ & $1,014.9 \pm 1,801.9$ \\
\hline$P$-value & & $<0.001$ & $<0.001$ & $<0.001$ & $<0.001$ \\
\hline
\end{tabular}

constitute $50 \%-75 \%$ of the economic load of COPD because of extra emergency department applications and increased hospitalizations. ${ }^{18}$ Studies on the causality between treating exacerbations and slowing down the progression of COPD have indicated that successful management of the exacerbations is the main approach for reducing the costs, both directly and also indirectly, by slowing the progression of the disease. ${ }^{1,16}$ In this study, the total cost of hospitalization due to COPD exacerbations was found to be $\$ 808$. Previous studies have reported a wide range of cost per hospitalization (between \$612 and \$9,545). 5-7,19-24

In this study, while the cost of hospital stays composes the main portion of total costs $(40.7 \%)$, other costs such as those for medication, consumption of materials, consultations, and doctor visits, plus laboratory expenditures, constitute a significant percentage of total costs. In previous studies, the main cost is associated with hospital stays, followed by laboratory expenditures and medication costs. ${ }^{19,20}$ Therefore, a major reduction in COPD-related costs could be achieved by reducing the expenditures of staying in hospital.

\section{Comorbidities in COPD}

The main reason for the hospitalization of COPD patients is the presence of comorbidities with or without exacerbation: these patients have a higher prevalence of comorbid diseases compared to the general population. ${ }^{12,13}$ Although the mechanisms by which COPD-related comorbidities develop are still unclear, it has been suggested that systemic inflammation contributes to the disease process. However, the causes of comorbidities are more likely to be multifactorial (eg, inactivity, poor diet, hypoxia, and inflammation). ${ }^{1}$ Comorbidity existence is a critical factor associated with high mortality in COPD. ${ }^{12,13}$ Diabetes, heart failure, renal failure, cancer, and neuropsychiatric diseases are common with aging and often occur together, ${ }^{25,26}$ if any of these diseases exists, the possibility that others exist is higher in these individuals compared to healthy adults. ${ }^{27}$ In a previous study, more than three comorbid disorders were observed in $46 \%$ of COPD patients. ${ }^{28}$ In our study, two comorbid diseases were recorded in $28.9 \%$ of patients, the most common being hypertension, followed by other cardiovascular diseases, such as coronary artery disease 
and congestive heart failure, as well as diabetes mellitus. Similarly, in the literature, cerebrovascular disease, mainly hypertension, was reported to be the most common comorbidity in patients with COPD. ${ }^{13,14,29}$ In a study by Miyazaki et al, ${ }^{30} 36 \%$ of patients with COPD had hypertension and $32 \%$ had cardiovascular disease, while $25 \%$ had cancer, $17 \%$ had mental disorders, and $15 \%$ had diabetes mellitus. In this study, comorbid disease was observed in 808 patients; the most common comorbid disease was hypertension, followed by other cardiovascular diseases and diabetes, anemia, anxiety/depression, and other disorders.

\section{Cost of COPD exacerbations and comorbidities}

In this study, the exacerbation-related costs for patients with at least one comorbidity totaled $\$ 2,273$, whereas the costs for patients with COPD exacerbations but no comorbidity totaled $\$ 523$. The presence of comorbidities significantly increased the total costs associated with COPD exacerbations. The costs of COPD exacerbation associated with pneumonia, diabetes mellitus, heart failure, hypertension, coronary artery disease, anemia, lung cancer, arrhythmia, and anxiety/depression were found to be significantly higher than those associated with COPD without comorbidities. Comorbidities most significantly related to high costs were anemia, coronary artery disease, and hypertension, likely because they are the most common comorbid diseases.

Previous studies have demonstrated a direct relationship between the yearly costs of COPD and the number of comorbid diseases. ${ }^{15,23,31}$ Perera et al ${ }^{23}$ assessed the factors responsible for increasing costs for patients hospitalized due to exacerbation and reported a significant relation between increased costs and comorbidities, such as acute myocardial infarction, congestive heart failure, cerebrovascular disease, lung cancer, arrhythmia, pulmonary thromboembolism, and low body weight. COPD patients with comorbidities require hospitalization, which lead to increased costs. Moreover, $\sim 50 \%$ of COPD patients use cardiovascular medications and, more frequently, analgesic, antibiotics, and psychotherapeutic drugs. ${ }^{31}$ One study of COPD patients with comorbid diseases showed direct costs that were 4.7 times higher than those for COPD patients with no comorbidity. ${ }^{14}$ Similarly, our study found that the costs associated with comorbid diseases were 4.3 times higher. Pneumonia was found to be associated with both direct and indirect costs. Some studies have demonstrated that pneumonia increases total direct costs by 1.9-2.5 times for outpatients and by 3.39-4.72 times for hospitalized patients. ${ }^{15,32}$ In this study, costs were 1.6 times higher in patients with pneumonia compared to those without pneumonia.

Dalal et $\mathrm{al}^{22}$ observed that yearly direct costs were $38 \%$ more in COPD patients with cardiovascular disease compared to patients with COPD only. Pasquale et $\mathrm{al}^{16}$ investigated the yearly costs of COPD cases and noted that the existence of cardiovascular disease (1.69 times higher) and diabetes mellitus (1.46 times higher) was found to be associated with increased yearly costs for COPD patients. In our study, cardiovascular disease (3.4 times higher) and diabetes mellitus (2.4 times higher) were found to be related to increased costs. In a study performed by Halpern et al, ${ }^{17}$ anemia increased costs for hospitalized patients by $\sim 2.5$ times. This ratio was 3.5 times in our study. In addition, in previous studies, hypertension, cor pulmonale, chronic renal failure, peptic ulcer, liver disease, and apnea were shown to increase the total cost of COPD. ${ }^{6,7,33-35}$

\section{Other clinical factors affecting the cost of COPD}

In this study, age $>65$ years, female gender, hospitalization in an intensive care unit, intubation, noninvasive mechanical ventilation, and a long duration of hospitalization were factors increasing costs for patients with COPD exacerbations who required hospitalization. The mean duration of hospitalization was 8.1 days in this study. In previous studies, the mean duration was 4.5-14.5 days. ${ }^{5-7,19,22-24}$ A longer hospital duration is also associated with increased daily costs due to treatment-resistant, severe cases with many accompanying comorbidities in addition to increased expenditures for hospital stays. The relationship between increased costs and a lengthy hospital stay has been demonstrated in many studies. ${ }^{6,23,33}$

In our study, the rate of exacerbations requiring hospitalization in intensive care units was $16 \%(n=841)$, and the mean hospitalization duration was 10.4 days. The mean cost of hospitalization in an intensive care unit was $\$ 1,977$, which was 3.4 times higher compared to cases without intensive care unit hospitalization. Being followed by noninvasive mechanical ventilation or intubation was also found to be associated with increased costs. In cases who require hospitalization in intensive care units, the costs of laboratory tests and medications increase as hospitalization time is extended. Similar to our study, Dalal et $\mathrm{al}^{22}$ reported that the duration of hospitalization was longer in terms of exacerbations requiring hospitalization in intensive care units and the cost was nearly doubled for cases in which patients were hospitalized in intensive care units compared to those who did not require 
intensive care hospitalization. Stanford et $\mathrm{al}^{36}$ found that costs were nearly six times higher, and Örnek et $\mathrm{al}^{6}$ noted that costs were tripled for COPD patients hospitalized in intensive care units.

\section{Limitations}

Although this study is valuable because it included a large number of patients and exacerbations, it had some limitations that need to be mentioned. First, the retrospective design may have led to data loss, which precludes a definitive conclusion. Furthermore, our results reflect COPD-related costs in Turkey, which complicates the generalization of our data to other countries.

\section{Conclusion}

Comorbidities have an important role in the total costs of acute exacerbations of COPD. Strategies for the prevention, diagnosis, and effective management of comorbidities would decrease the overall financial burden associated with acute exacerbations of COPD.

\section{Clinical implications}

The costs of acute exacerbations of COPD are mainly associated with comorbidities. During routine follow-up, questioning the patient about, as well as managing the most common comorbidities, such as diabetes mellitus, hypertension, and arrhythmia might reduce the cost load. Furthermore, COPD patients have a sedentary lifestyle due to limitations of daily physical activities, which causes a tendency toward anxiety and depression. Thus, during routine visits, patients with advanced COPD should be evaluated with respect to their psychological mood and be provided with psychosocial support, pulmonary rehabilitation, and physical exercise programs. The implementation of these measures would decrease the cost load of COPD and increase the costeffectivity of managing the disease. Finally, the prevention of pneumonia through vaccination of COPD patients and avoiding the usage of unnecessary and high-dose inhaled steroids should also be considered in efforts to decrease the cost of COPD management.

\section{Author contributions}

SD designed the study, collected the data, and prepared the article. AŞ and YA prepared the article, analyzed the data, and searched the literature. JÇE and MHÖ reviewed the article. All authors contributed toward data analysis, drafting and critically revising the paper and agree to be accountable for all aspects of the work.

\section{Disclosure}

The authors report no conflicts of interest in this work.

\section{References}

1. Global Initiative for Chronic Obstructive Lung Disease. Global Strategy for the Diagnosis, Management, and Prevention of Chronic Obstructive Pulmonary Disease. 2016. Available from: http://goldcopd.org/globalstrategy-diagnosis-management-prevention-copd-2016/. Accessed August 20, 2016.

2. World Health Organization [webpage on the Internet]. Global Health Observatory Data Repository. 2016. Available from: http:// apps.who.int/gho/data/node.main.CODWORLD?lang=en. Accessed August 20, 2016.

3. Murray CJ, Lopez AD. Alternative projections of mortality and disability by cause 1990-2020: Global Burden of Disease Study. Lancet. 1997;349(9064):1498-1504.

4. Foo J, Landis SH, Maskell J, et al. Continuing to confront COPD international patient survey: economic impact of COPD in 12 countries. PLoS One. 2016;11(4):e0152618.

5. Ozkaya S, Findik S, Atici AG. The costs of hospitalization in patients with acute exacerbation of chronic obstructive pulmonary disease. Clinicoecon Outcomes Res. 2011;3:15-18.

6. Örnek T, Tor M, Altın R, et al. Clinical factors affecting the direct cost of patients hospitalized with acute exacerbation of chronic obstructive pulmonary disease. Int J Med Sci. 2012;9(4):285-290.

7. Emre JC, Özdemir O, Baysak A, et al. Clinical factors affecting the costs of hospitalized chronic obstructive pulmonary disease exacerbations. Eurasian J Pulmonol. 2014;16:180-183.

8. O'Reilly CF, Williams AE, Holt K, Rice L. Defining COPD exacerbations: impact on estimation of incidence and burden in primary care. Prim Care Respir J. 2006;15(6):346-353.

9. Hurst JR, Vestbo J, Anzueto A, et al; Evaluation of COPD Longitudinally to Identify Predictive Surrogate Endpoints (ECLIPSE) Investigators. Susceptibility to exacerbation in chronic obstructive pulmonary disease. N Engl J Med. 2010;363(12):1128-1138.

10. Berry CE, Wise RA. Mortality in COPD: causes, risk factors, and prevention. COPD. 2010;7(5):375-382.

11. McGarvey LP, John M, Anderson JA, Zvarich M, Wise RA; TORCH Clinical Endpoint Committee. Ascertainment of cause-specific mortality in COPD: operations of the TORCH clinical endpoint committee. Thorax. 2007;62(5):411-415.

12. Sin DD, Anthonisen NR, Soriano JB, Agusti AG. Mortality in COPD: role of comorbidities. Eur Respir J. 2006;28(6):1245-1257.

13. Mannino DM, Thorn D, Swensen A, Holguin F. Prevalence and outcomes of diabetes, hypertension and cardiovascular disease in COPD. Eur Respir J. 2008;32(4):962-969.

14. Mapel DW, Hurley JS, Frost FJ, Petersen HV, Picchi MA, Coultas DB. Health care utilization in chronic obstructive pulmonary disease. A casecontrol study in a health maintenance organization. Arch Intern Med. 2000;160(17):2653-2658

15. Polsky D, Bonafede M, Suaya JA. Comorbidities as a driver of the excess costs of community-acquired pneumonia in U.S. commerciallyinsured working age adults. BMC Health Serv Res. 2012;12:379.

16. Pasquale MK, Sun SX, Song F, Hartnett HJ, Stemkowski SA. Impact of exacerbations on health care cost and resource utilization in chronic obstructive pulmonary disease patients with chronic bronchitis from a predominantly medicare population. Int J Chron Obstruct Pulmon Dis. 2012;7:757-764.

17. Halpern MT, Zilberberg MD, Schmier JK, Lau EC, Shorr AF. Anemia, costs and mortality in chronic obstructive pulmonary disease. Cost Eff Resour Alloc. 2006;4:17.

18. Celli BR, MacNee W; ATS/ERS Task Force. Standards for the diagnosis and treatment of patients with COPD: a summary of the ATS/ ERS position paper. Eur Respir J. 2004;23(6):932-946. 
19. Simoens S, Decramer M, De Coster S, Celis G, Laekeman G. Clinical and economic analysis of antimicrobial therapy of chronic obstructive pulmonary disease exacerbations. Int J Clin Pract. 2007;61(2):200-206.

20. O'Reilly JF, Williams AE, Rice L. Health status impairment and costs associated with COPD exacerbation managed in hospital. Int J Clin Pract. 2007;61(7):1112-1120.

21. Niederman MS, McCombs JS, Unger AN, Kumar A, Popovian R. Treatment cost of acute exacerbations of chronic bronchitis. Clin Ther. 1999;21(3):576-591.

22. Dalal AA, Shah M, D'Souza AO, Rane P. Costs of COPD exacerbations in the emergency department and inpatient setting. Respir Med. 2011; 105(3):454-460.

23. Perera PN, Armstrong EP, Sherrill DL, Skrepnek GH. Acute exacerbations of COPD in the United States: inpatient burden and predictors of costs and mortality. COPD. 2012;9(2):131-141.

24. Varol Y, Varol U, Başer Z, Usta L, Balcı G, Özacar R. The cost of COPD exacerbations managed in hospital. Turk Toraks Derg. 2013; 14(1):19-23.

25. Bousquet J, Anto JM, Sterk PJ, et al. Systems medicine and integrated care to combat chronic noncommunicable diseases. Genome Med. 2011;3(7):43.

26. Barnett K, Mercer SW, Norbury M, Watt G, Wyke S, Guthrie B. Epidemiology of multimorbidity and implications for health care, research, and medical education: a cross-sectional study. Lancet. 2012; 380(9836):37-43.

27. Hidalgo CA, Blumm N, Barabasi AL, Christakis NA. A dynamic network approach for the study of human phenotypes. PLoS Comput Biol. 2009;5(4):e1000353.
28. Sharafkhaneh A, Petersen N, Yu HJ, Dalal AA, Johnson ML, Hanania NA. Burden of COPD in a government health care system: a retrospective observational study using data from the US Veterans Affairs population. Int J Chron Obstruct Pulmon Dis. 2010;5:125-132.

29. Fumagalli G, Fabiani F, Forte S, et al. INDACO project: a pilot study on incidence of comorbidities in COPD patients referred to pneumology units. Multidiscip Respir Med. 2013;8(1):28.

30. Miyazaki M, Nakamura H, Chubachi S, et al. Analysis of comorbid factors that increase the COPD assessment test scores. Respir Res. 2014;15:13.

31. Halpin DM, Miravitlles M. Chronic obstructive pulmonary disease: the disease and its burden to society. Proc Am Thorac Soc. 2006;3(7): 619-623.

32. Lin J, Li Y, Tian H, et al. Costs and health care resource utilization among chronic obstructive pulmonary disease patients with newly acquired pneumonia. Clinicoecon Outcomes Res. 2014;6:349-356.

33. Chen YH, Yao WZ, Cai BQ, et al. Economic analysis in admitted patients with acute exacerbation of chronic obstructive pulmonary disease. Chin Med J. 2008;121(7):587-591.

34. Agusti A. Systemic effects of chronic obstructive pulmonary disease: what we know and what we don't know (but should). Proc Am Thorac Soc. 2007;4(7):522-525.

35. Shaya FT, Lin PJ, Aljawadi MH, Scharf SM. Elevated economic burden in obstructive lung disease patients with concomitant sleep apnea syndrome. Sleep Breath. 2009;13(4):317-323.

36. Stanford RH, Shen Y, McLaughlin T. Cost of chronic obstructive pulmonary disease in the emergency department and hospital. Treat Respir Med. 2006;5(5):343-349.
International Journal of COPD

\section{Publish your work in this journal}

The International Journal of COPD is an international, peer-reviewed journal of therapeutics and pharmacology focusing on concise rapid reporting of clinical studies and reviews in COPD. Special focus is given to the pathophysiological processes underlying the disease, intervention programs, patient focused education, and self management protocols.

\section{Dovepress}

This journal is indexed on PubMed Central, MedLine and CAS. The manuscript management system is completely online and includes a very quick and fair peer-review system, which is all easy to use. Visit http://www.dovepress.com/testimonials.php to read real quotes from published authors. 